Research Article

\title{
Framework for Designing Project Delivery and Contract Strategy in Chinese Construction Industry Based on Value-Added Analysis
}

\author{
Jiyong Ding $\mathbb{D}^{1},{ }^{1}$ Na Wang $\mathbb{D}^{1},{ }^{1}$ and Leichuang $\mathrm{Hu} \mathbb{D}^{2}$ \\ ${ }^{1}$ Institute of Engineering Management, Hohai University, Nanjing, China \\ ${ }^{2}$ China Three Gorges International Corporation, Beijing, China \\ Correspondence should be addressed to Jiyong Ding; jyding@hhu.edu.cn \\ Received 15 December 2017; Accepted 2 April 2018; Published 8 May 2018 \\ Academic Editor: Flora Faleschini
}

Copyright (c) 2018 Jiyong Ding et al. This is an open access article distributed under the Creative Commons Attribution License, which permits unrestricted use, distribution, and reproduction in any medium, provided the original work is properly cited.

\begin{abstract}
A project delivery method (PDM) and project contract strategy (PCS) are two critical factors for project success in construction industry. Currently, there are several options available for them in the construction industry, with several innovative PDMs and PCSs emerging along with the development of the industry. This paper maintains that the PDM should be designed in combination with the PCS given their close relationship. This paper focuses on the design of project delivery and contract strategy (PDCS), with the aim of developing a conceptual framework for the PDCS design. The design process is divided into two stages: preliminary design and detailed design, taking engineering design as a frame of reference. In the design process, the value-added analysis of project objectives is adopted as a tool to make decisions at different stages. The framework proposed in this paper is intended to provide a more distinct and direct path to improving PDCS selection or design, as well as enhancing the reliability of decision-making.
\end{abstract}

\section{Introduction}

According to the data released by the National Bureau of Statistics of China, the total output value of the national construction industry in 2017 reached 213954 billion yuan, with a $10.5 \%$ year-on-year growth [1]. As for the Chinese construction industry in 2018, relevant experts stated that it will continue to make more contributions to promote national urban and rural construction, as well as new urbanization development, improve people's living conditions, absorb the rural labor force, and relieve the pressure of social employment. The construction industry will still be an important pillar industry of the national economy of China. At the same time, the construction industry should actively develop "internal strength," establish itself as an internationalized industry, and be in line with international standards. It should also improve the quality of technology and management, while the project delivery method innovation is one of the key issues that deserve in-depth study in the Chinese construction industry. For a long time, the traditional approach is widely used, which often exposes many disadvantages in some engineering applications. It can no longer meet the needs of the development of the Chinese construction industry. At present, a lot of complex construction projects are calling for other options of the project delivery system.

The project delivery method/system (PDM/PDS), sometimes also known as the project procurement method/system [2-5], can also be called the project transaction method from the perspective of transaction [6]. Despite many efforts to define the project delivery system, there is no generally accepted definition for this term. Considering that the design and construction are two of the most important activities in any project implementation, project delivery systems can be classified into two categories according to whether the design and construction are integrated and achieved by a single contract. The typical methods of these two categories are design-bid-build (DBB) and design-build (DB). Under the 
DBB method, the design and construction are not integrated, and they are achieved by separate contracts. By contrast, the design and construction are integrated and achieved by a single contract with DB. In the construction practice, these two kinds of PDMs have been developing over decades and deriving many specific PDMs applicable to specific projects. For example, within DBB, the construction service can be provided by one contractor known as the general contractor (GC) or can be divided into several parts to be achieved by several different contactors, which is known as separate primes/parallel primes [7]. Under the DB approach, new PDMs such as design-buildoperate (DBO) and design-build-finance-operate (DBFO) emerge that are extended from DB [8]. Besides, engineeringprocurement-construction (EPC) is quite similar to DB since it also overlaps the design and construction. Although EPC predates $\mathrm{DB}$ as a formal concept, the idea of $\mathrm{DB}$ is more fundamental. Therefore, EPC can also be taken as one variation of $\mathrm{DB}$ to some degree. In recent years, with the gradual spreading of the building information model (BIM) technology, the integrated project delivery (IPD) appears to be known as an innovative delivery method, but naturally it also comes into being based on existing delivery methods [9].

Seen from the application and evolution of project delivery systems, it is evident that they develop along with the development of economic society. More than 200 years ago, combined delivery systems (i.e., the concurrent delivery of design and construction services, such as the modern DB method) were widely used in American infrastructure projects, but it brought about a lot of quality-related and safetyrelated issues, which made people realize that the DB method is not appropriate under the technical and management level at that time [10]. Therefore, DB was limited to use in the federal projects at the beginning of the last century, and the application of DBB was compulsorily required in 1926 with the Public Buildings Act. However, DB attracted more attention again in 1980s with the development of engineering technologies and management theories, as well as project size and complexity [10]. Until the end of the last century, the market for DB grew steadily in the private sector and was increasingly used in the public sector.

There is no delivery system that is equally applicable to all kinds of projects, either in developed countries or developing countries. DB's market share is gradually increasing, but many projects still use traditional DBB. In China, most construction projects used DBB over the past decades, but DB is developing fast and is now widely used in the petrochemical industry and nuclear power industry. It remains relatively less used in the building industry [11]. The choice of a project delivery system is influenced not only by the technical level and management system, but also by other important factors such as project characteristics and project environment. It is generally accepted that the PDM should be selected taking into account all kinds of important factors for a given project. Several studies have concentrated on decision methods of PDM selection based on an analysis of selection factors $[7,12,13]$, but different factors are identified from different perspectives, and sometimes the factors may not be directly related to project objectives, thus making the corresponding results unconvincing.

Essentially, project delivery systems are products of design, not simple selection [14]. The research on the PDM design should be directly connected to project objectives since the core aim of the project management is to achieve project objectives, while the PDM is a critical factor for project success. For a specific project, what delivery method should be adopted is an important decision that should be made carefully. Since this is influenced by various kinds of factors, it is necessary to design a specific delivery system taking account into the specific characteristics and environment of a specific project, just like the engineering structure design. Through optimization of the design, a scientific and reasonable project delivery system is expected to maximize the project performance in the implement process, namely, to achieve the added value of project objectives.

On the other hand, the term "project delivery" is often used together with "contracting strategy" or "contract strategy." In fact, contracting strategy is a supporting means of successful implementation of the project delivery approach [15]. Neither contracting strategy nor project delivery can function independently when they are separate. Therefore, contract strategy should be integrated with project delivery to be selected in project delivery and contract strategy (PDCS) selection or design [16].

As a matter of fact, both research and practice show that one of the key success factors of a construction project is the project execution planning, while the core of this plan is the project delivery method and contract strategy [8]. Therefore, choosing the right mode is one of the key factors that determine the success of a construction project [17]. This paper tries to explore the design of PDCS from a value-added perspective.

\section{Methodology}

This paper attempts to explore the joint planning between PDM and PCS, aiming to put forward a conceptual framework for the design of PDCS. First of all, this paper makes a thorough and in-depth review and analysis of the previous studies on the PDM and PCS and compares them with related concepts including the owner's management method and contractor selection method, so as to identify the research gaps arising from previous studies. In terms of the PDM, the authors support the opinion that the relationship between design and construction is perceived to have the most bearing on the evolution of a consequent choice of PDMs and accordingly propose a simpler classification of PDMs based on whether design and construction are integrated and achieved by a single contract. In doing so, this paper maintains that $\mathrm{DB}$ and $\mathrm{DBB}$ are the two fundamental PDMs, since design and construction are separated and achieved by separate contracts under $\mathrm{DBB}$, while design and construction are integrated and achieved by a single contract under DB.

Based on the review of previous studies and theoretical analysis, this paper then tries to set up a conceptual 
TABLE 1: Comparison of the PDM with other related concepts.

\begin{tabular}{|c|c|c|}
\hline Concept & Definition & Types \\
\hline Project delivery method & $\begin{array}{l}\text { Defines the sequence of project phases, parties } \\
\text { involved in the project and implicitly assigned } \\
\text { roles, and responsibilities to project parties }\end{array}$ & $\mathrm{DBB}, \mathrm{DB}, \mathrm{CMR}, \mathrm{IPD}$, and so on \\
\hline Management method & $\begin{array}{l}\text { The mechanics by which construction is } \\
\text { administered and supervised }\end{array}$ & $\begin{array}{l}\text { Either retained by the owner agency or is } \\
\text { outsourced including CMA and PM }\end{array}$ \\
\hline $\begin{array}{l}\text { Procurement method/selection } \\
\text { method }\end{array}$ & $\begin{array}{c}\text { Equates to the procedures through which } \\
\text { a designer or a constructor is selected for the } \\
\text { project }\end{array}$ & $\begin{array}{c}\text { Some of the most practiced procurement } \\
\text { methods are lowest bid, best value, and } \\
\text { qualifications-based selection }\end{array}$ \\
\hline $\begin{array}{l}\text { Payment method/contracting } \\
\text { method }\end{array}$ & $\begin{array}{l}\text { How the owner wants to pay for the services } \\
\text { provided }\end{array}$ & $\begin{array}{c}\text { Unit price, GMP, cost plus fee, lump sum, and so } \\
\text { on }\end{array}$ \\
\hline
\end{tabular}

framework for the PDCS design. The authors suggest that the objective of the PDCS design boils down to achieving the added value in terms of project goals and identify the key factors affecting the PDCS design. As for the design process, the authors propose that the design process of PDCS can be similar to that of an engineering structure; thus the design process is divided into two steps, preliminary design and detailed design. DBB or DB, as a fundamental PDM, will be selected in the preliminary design stage, as a basis for the detailed design. Then in the detailed design, the most proper variant will be selected or a new variant will be designed based on DB or DBB according to the result of the first step, and the contract strategy will be determined to match with the PDM. When selecting DB or DBB in the first stage and determining the variant of them in the detailed design, the value-added analysis of project objectives is conducted to make the decisions.

\section{Related Work}

Systematic research on project delivery systems started from the latter part of last century, especially when DB became popular again in the construction industry. The related research can be mainly classified into the following categories: performance comparison of different PDMs and PDM selection. This part focuses on related work about the PDM and introduces contract strategy briefly as well.

3.1. Project Delivery System. Up till now, there is no generally accepted definition for the project delivery system. Some people state that a "project delivery system defines the sequence of project phases, parties involved in the project and implicitly assigned roles, and responsibilities to project parties" [16]. The Associated General Contractors defines the project delivery method as "the comprehensive process of assigning the contractual responsibilities for designing and constructing a project. A delivery method identifies the primary parties taking contractual responsibility for the performance of the work" [18]. These documented definitions do not necessarily comply with each other, and one may find minor or even major differences in them. It becomes even more complicated when some authors combine the payment methods, procurement methods, and management methods with the PDMs [19]. Here, the concept of the procurement method is sometimes equal to the delivery method, especially in countries like UK, but now, in the USA, it is often used to refer to the selection method for the contractor or architect. According to current references $[7,16,20]$, a comparison of these related concepts is shown in Table 1.

As shown in Table 1, several types of project delivery methods are currently available. The PDMs are often closely related to one another, which makes the classification of PDMs difficult [5]. The Construction Industry Institute (CII) maintains that there are really only three fundamental PDMs: design-bid-build (DBB), design-build (DB), and construction manager-at-risk (CMR) [21, 22]. Rwelamila and Edries proposed an amalgam of the various classifications from perspectives of developing countries [5]. They classified PDMs into three categories: separated and cooperative systems including conventional systems (DBB) and their variants; integrated systems including $\mathrm{DB}$ and their variants; and management-oriented systems including management contracting and construction management.

Wang et al. maintained that the design depth and implementation stage of different delivery systems are different from each other [6]. Therefore, a delivery system spectrum can be structured based on design depth and construction stages, as shown in Figure 1.

Similarly, Figure 2 displays different types of project delivery approaches that combine various phases of the project life cycle [23-25]. Many of these project delivery approaches extend far beyond the scope of design-build contracting by placing increasing functional responsibilities.

Although different categorizations for PDMs are found in the literature, this paper supports the opinion that the relationship between design and construction is perceived to have the most bearing on the evolution of a consequent choice of project delivery systems [26]. Thus, as shown in Figure 3, a simpler classification of PDMs is proposed based only on whether the design and construction are integrated and achieved by a single contract, without taking into account financing, operation, and so on. Besides, this paper distinguishes the concept of the delivery system and management method as noted in Table 1, so methods like CM agency (CMA) are in essence management methods, not project delivery systems. Therefore, there are essentially only two fundamental project delivery methods: DBB and DB. There is a multitude of names for PDMs throughout the 


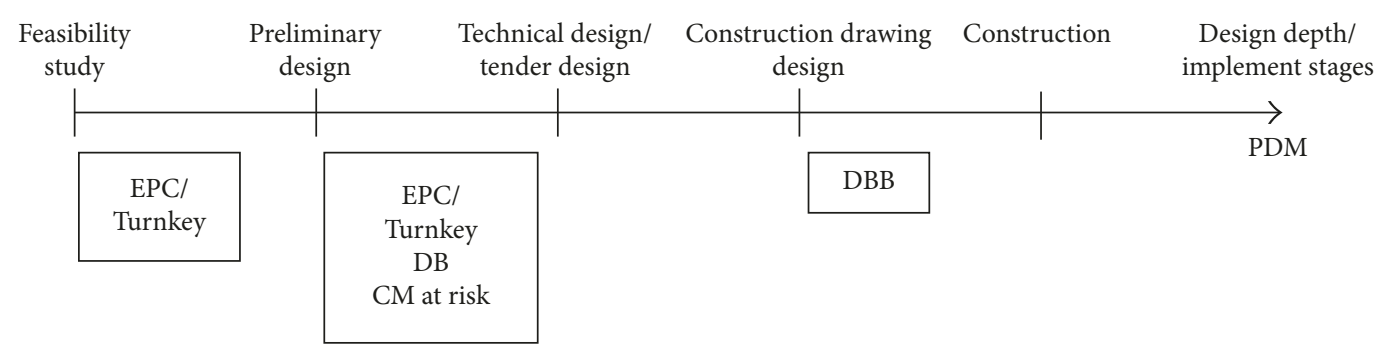

FIGURE 1: PDM spectrum. Note: the scope of each PDM is from the left point of the coordinate PDM.

Full delivery or program management

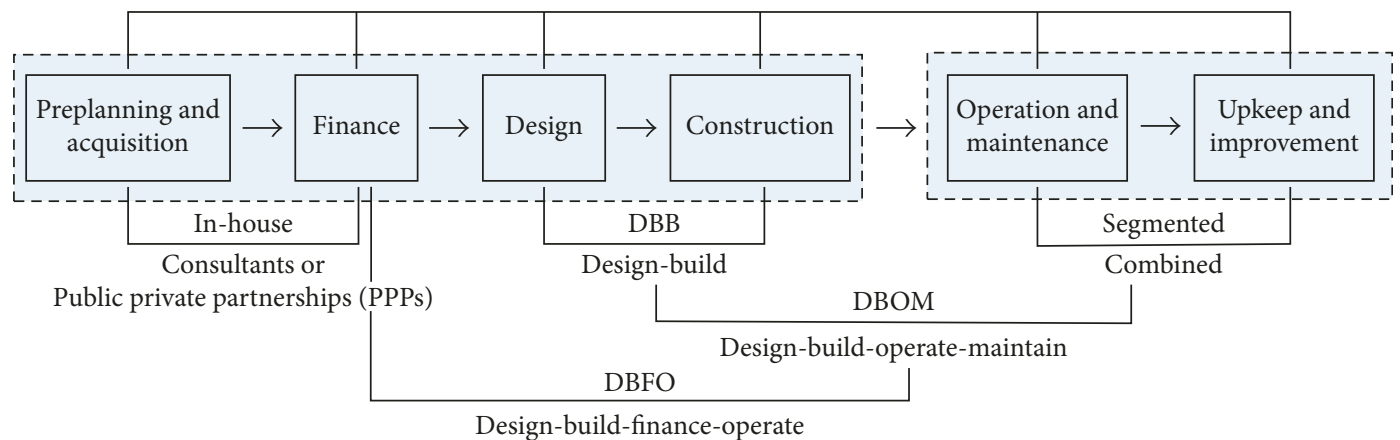

Figure 2: Alternative PDMs.

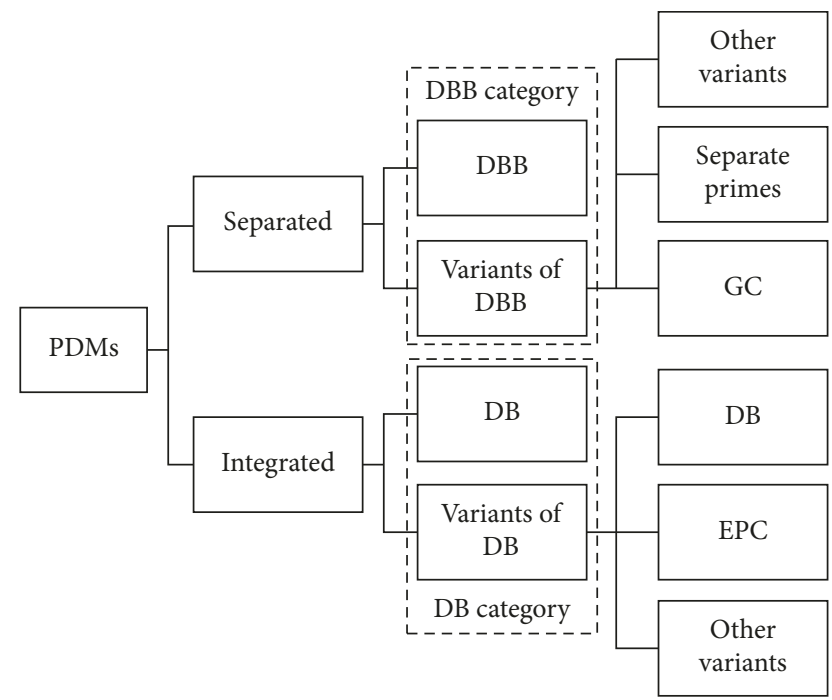

Figure 3: Classification of PDMs. Note: EPC may predate DB, but $\mathrm{DB}$ is always taken as one fundamental project, so here we take EPC as one variant of DB.

construction industry which are mainly hybrids or modified versions of these two methods.

3.2. Performance Comparison of PDMs. Among the existing studies on performance comparison of different PDMs, $\mathrm{DBB}, \mathrm{DB}$, and construction management at risk (CMR) are the ones that were mostly studied. Each of these PDMs has their own advantages and disadvantages [27-30], as demonstrated by the associated research. Konchar and Sanvido empirically compared the cost, schedule, and quality performance of three project delivery systems: DBB, DB, and CMR, using project-specific data collected from 351 U.S. building projects $[31,32]$. The research results showed that the unit cost for $\mathrm{DB}$ was $6.1 \%$ less than DBB projects; the expected growth for DBB, DB, and CMR were $4.4 \%, 0$, and 0 , respectively; the construction speed for $\mathrm{DB}$ projects was $12 \%$ faster than that for DBB projects; while the delivery speed for DB projects was 33.5\% faster than that for DBB projects. Qiang et al. employed the random effect meta-analysis model to statistically integrate results in previous studies. The meta-analysis results, verified by the robust test, show that DB projects achieve significantly lower cost growth on average. Further meta-analyses on different groups of studies reflect that the DB system performs worse in public projects. DBB is more conducive to cost growth control under complex project conditions. Cost growth improvements induced by DB system experienced growth initially, followed by shrinkage afterwards due to policy changes. This reminds owners that the PDM should be selected according to specific project conditions [33]. Since each project is unique, while project performance is influenced by many factors except the PDM, the performance comparison results are difficult to be reliable.

A study by Rojas and Kell empirically compared cost growth performance of the CMR and DBB methods in Pacific Northwest public school projects. Results show no statistically significant difference between CMR and DBB in construction change order costs, school project costs exceeding the GMP in $75 \%$ of the cases, and a statistically significant difference in cost growth between $\mathrm{CMR}$ and $\mathrm{DBB}$ projects during buyout, making CMR projects less efficient 
at controlling cost growth at buyout [34]. Research by Hale et al. statistically analyzed cost and schedule performance of a homogeneous sample of U.S. Navy Bachelor Enlisted Quarters constructed under the Military Construction program by using DB and DBB methods. Thirty-nine DBB projects and $38 \mathrm{DB}$ projects built from fiscal years 1995 to 2004 were analyzed. The study findings showed that among the three cost-related metrics, only cost growth of $\mathrm{DB}$ projects was significantly less than that of DBB projects. However, all the schedule-related metrics of DB projects were significantly superior to that of DBB projects [35]. Rosner et al. compared the performance of the DB delivery method with the traditional DBB approach for the Air Force military construction program. Results show that the $\mathrm{DB}$ mean cost growth was $4.52 \%$, while the traditional $\mathrm{DBB}$ average was $6.42 \%$, and the mean traditional DBB total project time was 3.05 years, while the mean DB total project time was 3.28 years, which means that the DB method had better performance for cost growth, while the traditional DBB method performed significantly better in terms of total project time [36]. It can be seen that most of the above studies concluded that DB performs better both in schedule and cost.

However, there are also some studies that do not fully support this conclusion. For example, research performed by the Construction Industry Institute (CII) and sponsored by the National Institute for Standards and Technology (NIST) in 2002 measured the effects of the DB and DBB delivery systems on project performance of industrial building projects. This research concluded that owner-submitted DB projects outperformed DBB projects in cost, schedule, changes, rework, and practice use, although statistically significant differences were found only for schedule, changes, rework, and practice use. Contractor-submitted DB projects overall outperformed DBB projects in changes, rework, and practice use, but the difference was statistically significant only for change performance, while contractor-submitted DBB projects overall outperformed DB projects in schedule, and the difference was statistically significant (CII and NIST, 2002). Yun and Jung present the development, validation, and implementation of an innovative comprehensive project performance metric specifically developed for architecture, engineering, and construction (AEC) projects. The project quarterback rating $(\mathrm{PQR})$ combines key performance metrics of a project into a single number to provide a basis for quantifying project success. In this paper, $\mathrm{PQR}$ scores are calculated for projects completed under different delivery systems. The results clearly show differences in performance for projects delivered with DBB, CMR, DB, and IPD [37]. Qiang et al. constructed a matching relationship model between key factors in PDM and project conditions and analyzed the impact of matching relationships on project performance and its functioning mechanism, and the results showed that the more reasonable the matching relationship between the $\mathrm{PDM}$ and project conditions is, the better the project performance will be [38]. Although these studies get different results, but their ideas provide good references for the PDCS design in the future.

Some studies focus on special industries such as transportation projects $[25,38-41]$ and water/wastewater projects
[42-44], which make the comparison between different industries be possible, thus helping us to know more about the differences.

The studies mentioned above are from the perspective of a macroscopic view. In fact, each project is unique, and sometimes the difference between different projects is very big. Therefore, statistical analysis of performance data based on a limited number of projects is appropriate for the studied projects, but does not necessarily have universal significance. This may be the reason why different research projects may arrive at different conclusions.

3.3. Project Delivery Method Selection. The project delivery method has a great impact on project performance and construction quality $[3,5,45]$. While no project delivery option is perfect, one option may be better suited than another based on the unique requirements of a particular project [46]. Since owners have a number of objectives in terms of cost, schedule, quality, and level of control when deciding on the project delivery method, PDM selection is a problem with multiple objectives [19] and is not an easy task [12].

Most researchers explore the problem of PDM selection by determining the selection factors first, without using the study results of performance comparison noted above. Then, they adopt different kinds of decision analysis technology, such as AHP [46], Fuzzy [47], and weighted matrix [7] to select the most appropriate PDM.

In his dissertation, Ghavamifar provides a comprehensive solution for the common challenge of delivery method selection in the transit industry. The decision support system (DSS) developed in this research provides useful information and introduces the advantages and limitations of each PDM to the decision makers. A requisite well-structured decision-making process is embedded in the proposed framework of this decision aid tool that is reliable and sufficient to solve the problem of selecting an appropriate PDM. The dissertation covers four kinds of PDMs, that is, DBB, DB, CMR, and PPP [19].

Touran et al. identified those factors that drive the decision in the choice of the project delivery method. A rigorous case study analysis based on on-site structured interviews with the directors of several transit projects was used to identify decision drivers and the rationale behind the delivery method selection decision in transit agencies. The nine case studies conducted in this research represent a cross section of delivery methods, including design-bid-build/multiple prime, construction manager-at-risk, design/build, and design-buildoperate-maintain. The interviewees agreed that the use of alternative delivery methods have resulted in savings in schedule and cost for transit agencies. The research also found that achieving aggressive schedule compression is the most influential factor when selecting alternative delivery methods [22]. Liu et al. combined the literature review and questionnaire survey and explored the key contractor characteristics factors that affect project success under different PDMs using the rough set model. The findings indicate that a contractor's coordination and communications, a contractor's 
experience with similar types of projects, a contractor's ability in financial management, and a contractor's design capability are the four most key factors for project success under different PDMs [23]. This study provides theoretical support for the owner in selecting a PDM.

Xia et al. established a fuzzy multicriteria decision-making (FMCDM) model for selecting the most suitable DB operational variation. A three-round Delphi questionnaire survey was conducted to identify the selection criteria and their relative importance. A fuzzy set theory approach, namely, the modified horizontal approach with the bisector error method, was applied to establish the fuzzy membership functions, which enables clients to perform quantitative calculations on the performance of each DB operational variation. The FMCDM was developed using the weighted-mean method to aggregate the overall performance of DB operational variations with regard to the selection criteria [48].

Wang and Jian [14] and Wang et al. [6] regarded the project delivery system, contract, and transaction management as a whole based on project transaction element considerations. They put them into the same model and made a decision on their selection through system science. This research improved the selection of project delivery systems to some extent but is still dependent on the selection factors. Similarly, Anderson and Oyetunji [16] combined the project delivery method with contract strategy and developed a decision support tool for the selection of project delivery and contract strategy (PDCS).

From perspectives of history and development, it can be concluded that the PDM innovation should develop towards new PDMs to reflect the current trends. Therefore, new PDMs may share some features like integrated, cooperative, cost effective, sustainable, and lean, thus improving project performance with respect to project objectives $[15,49]$. In the future, we should consider these objectives to study the innovative design of the project delivery method.

3.4. Contract Strategy. Contract strategy defines how the parties are compensated for the services that they render in the execution of the project [16]. The terms "project delivery" and "contracting strategy" are often used together. In fact, contract strategy is a supporting means for successful implementation of the project delivery approach. Pishdad and Beliveau [15] selected some definitions for contracting/contract strategy from the existing literature, in which contracting/contract strategy determined how the owners pay for the services rendered by the service providers; the compensation approach for each contractual relationship [50]; means of contractually communicating expectation and basis of reimbursement [20]; allocation of the financial risks between the owner and the service providers [50]; and incentive to encourage contribution [51]. Based on these definitions, Pishdad and Beliveau proposed their own definition: contracting strategy describes the roles and responsibilities of the contracting parties; it determines the risk allocation strategies, methods of payment, basis for reimbursement, and incentive strategies for encouraging enhanced contribution [15].

This paper follows the definition made by Pishdad and Beliveau which includes risk allocation strategies, methods of payment, basis for reimbursement, and incentive strategies. These strategies are reflected by contracts to a great extent. On the other hand, at the stage of PDCS selection or development, the contact strategy should be determined firstly at a macrolevel, that is, determining contract type, while the detailed provisions containing other contract strategies need to be determined at a later time. Therefore, this paper uses contract type in the PDCS design or selection process to represent contract strategy. The main contract types include fixed price (lump sum, GMP, and unit price) and reimbursable (cost plus fee).

Based on the detailed literature review, Wang and Jian [14] developed a matrix to match contract-type and project delivery system, as shown in Table 2. However, this matrix is not applicable for projects with high risk and long duration.

The selection of an appropriate contract type is not a simple task. For a given project, project delivery system and the corresponding contract type should be adopted depending on many factors. The decision should be made based on a detailed analysis of the factors in the design process of PDCS.

3.5. Research Gaps. Most previous studies on project performance of $\mathrm{DB}$ and $\mathrm{DBB}$ project delivery methods included different types of projects with varied project sizes. But it is still difficult to conclude which kind of projects is well suited for each delivery system based on these studies. For a given project, which delivery system is appropriate is an important problem that needs specific analysis taking into account specific characteristics. So far, previous studies on the adoption of project delivery systems are based on influential factor analysis, which is too subjective and thus not convincing. The core of project management is to achieve project goals/objectives; therefore, it will be more reasonable if the PDM is adopted based on project goal analysis.

On the other hand, the existing research mainly focused on the selection of DB or DBB, while studies on variants of them or new PDM innovation are lacking, and there are not enough systematic studies performed on the specific and detailed methods. Besides, most of the studies separate project delivery and contract strategy.

\section{PDCS Design: Objective and Factors}

4.1. Objective of PDCS Design: To Achieve Added Value in terms of Project Goals. As noted above, PDCS is one critical factor for project success, which is traditionally defined as the degree to which project goals and expectations are met [52]. Thus, the objective of the PDCS design can be stated as to help achieve project goals, improve project performance, and ultimately ensure project success. As to these three concepts, Chan et al. stated that project success is the goal, and the objectives of budget, schedule, and quality are the three normally accepted criteria to achieve the goal. Each project has a set of goals to accomplish, and they serve as a standard to measure performance [52]. These concepts are closely related to each other and are macrolevel aspects of PDCS, which is not enough in the PDCS design. Therefore, 
TABle 2: Matching Matrix of the contract-type and project delivery system.

\begin{tabular}{|c|c|c|c|c|c|}
\hline \multirow{2}{*}{ PDS } & \multicolumn{5}{|c|}{ Contract type } \\
\hline & Lump sum & Unit price & Cost plus a fixed fee & Guaranteed maximum price (GMP) & Target price incentive contract \\
\hline DBB & $\Delta$ & $\star$ & $\Delta$ & - & - \\
\hline GC & $\star$ & $\star$ & $\Delta$ & - & - \\
\hline DB & - & $x$ & $\Delta$ & $\Delta$ & $\star$ \\
\hline $\mathrm{DP}$ & - & $x$ & $\Delta$ & $\Delta$ & $\star$ \\
\hline EPC & - & $x$ & $\Delta$ & $\Delta$ & $\star$ \\
\hline $\mathrm{CM}$ & - & $x$ & $\Delta$ & $\Delta$ & $\star$ \\
\hline PMT & $\Delta$ & - & - & $\Delta$ & $\star$ \\
\hline $\mathrm{PMC}$ & $\Delta$ & - & - & $\Delta$ & $\star$ \\
\hline $\mathrm{PM}$ & $\Delta$ & - & - & $\Delta$ & $\star$ \\
\hline
\end{tabular}

Note. $\mathrm{DBB}=$ design-bid-build; $\mathrm{GC}=$ general contractor; $\mathrm{DB}=$ design-build; $\mathrm{DP}=$ design-procurement; $\mathrm{EPC}=$ engineering-procurement-construction; $\mathrm{CM}=$ construction management; PMT = project management team; PMC = project management contractor; PM = project management; “ $\star$ " means well suited; " $\Delta$ " means fairly suited; "-" means not often used; " $x$ " means not suited.

this paper introduces "added value," a relatively microlevel concept, to more practically reflect the importance of an appropriate PDCS. Through the implementation of an appropriate PDCS, the added value will be achieved based on project objectives. For example, cost is one of the project objectives; thus, when cost savings has been attained, it means that the added value has been achieved in terms of cost objective. In a word, "added value" in this paper refers to the value added to different project objectives. The more the added value is achieved, the more successful the project is, and the better the corresponding PDCS is. Figure 4 shows the relationship between the added value and project objectives, project performance, and project success.

As mentioned above, there are different kinds of added values for different project objectives. While different projects have different objectives, identifying project goals/objectives is the first step in the decision-making process [53]. The project objective analysis is followed by the value-added analysis in the PDCS design. For a long time, the project objectives presented include quality, cost, schedule, risk, safety, and sustainability $[15,53]$. Pishdad and Beliveau concluded that the three emerging areas of green, integrated information, and life cycle cost considerations are not fully developed within the existing PDCS selection tools [15]. Future studies should investigate the impacts of these emerging project objectives if needed for a given project.

4.2. Factors Affecting PDCS Design. There are several factors/criteria/indicators that affect the selection/design of PDCS. It is important to seek an appropriate method to identify these factors, while the first important step is to make a categorization for them, which can help us to determine the factors more comprehensively. Many researchers identified different influential factors by adopting different classification methods. Alhazmi and McCaffer presented six criteria: project characteristics, market attributes, contractor and architect/engineer $(\mathrm{A} / \mathrm{E})$ needs, categories of client, client design organization, and the local design and construction regulations [54]. In the model developed by Khalil, decisionrelevant factors are grouped under three categories: project characteristics, owner's needs, and owner's preferences [55].

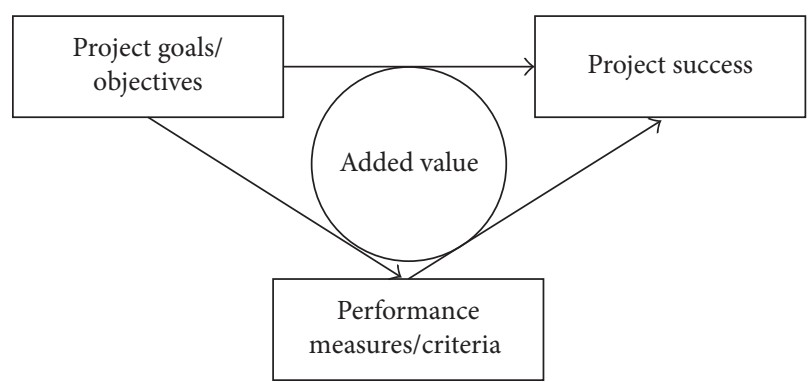

FIGURE 4: Relationship between the added value and related concepts.

In the guidelines prepared by GSFIC [56], the major factors are divided into five categories: schedule/necessity to overlap phases; ability to define the project scope/potential for changes; owner's internal resources and philosophy; desire for a single contract or separate contracts; and regulatory/legal or funding constraints. Mahdi and Alreshaid [57] divided the factors into seven categories that affect the identification of the optimum house construction delivery approach, that is, owner characteristics; project characteristics; design characteristics; regulatory; contractor characteristics; risk; and claims and disputes, and 34 factors were included in these seven categories. Mafakheri et al. [58] determined 13 factors through survey without making a classification. Ghavamifar [19] categorized the group of factors that should be considered when comparing the $\mathrm{DBB}, \mathrm{DB}$, and CMR into five groups: project-level issues, agency-level issues, public policy/regulatory issues, life cycle issues, and other issues. Through the literature review, Chen et al. [12] concluded that the indicators of PDS selection can be categorized into four groups, namely, project objectives, project characteristics, characteristics of owner and contractor, and external environment.

Several literature presented different categories of factors, but none of them proposed a definite criterion to distinguish the categories. In this study, we propose criteria based on transaction elements. In a previous research conducted in China, the project delivery system and contract type were studied from the perspective of transaction, and project delivery system was correspondingly called the project 
TABLE 3: Factors for PDCS selection/design (China perspective).

\begin{tabular}{lc}
\hline Category & Factor \\
\hline Transaction object-related factors (project characteristics) & $\begin{array}{c}\text { Project nature } \\
\text { Project size } \\
\text { Project complexity }\end{array}$ \\
\hline Transaction subject-related factors (owner's influences) & Construction interference between subprojects \\
\hline & $\begin{array}{c}\text { Owner's requirements on investment control } \\
\text { Owner's requirements on schedule control } \\
\text { Owner's requirements on quality control } \\
\text { Owner's risk preference }\end{array}$ \\
Transaction environment-related factors & $\begin{array}{c}\text { Owner's preference for the management method } \\
\text { Owner's project management ability }\end{array}$ \\
& $\begin{array}{c}\text { Site conditions } \\
\text { Land acquisition, demolition, and immigration }\end{array}$ \\
& National and local laws, regulations, and policies \\
Construction market development degree
\end{tabular}

transaction method [6]. For any transaction, the basic elements include transaction object, subject, environment, contract between transaction parties, and transaction management. Among these, the object and subject are most fundamental, as without these two elements the transaction cannot exist. With regard to construction project transaction, its success is mostly determined by the transaction object (i.e., the project itself), transaction subject (i.e., the owner, contractor, and other participants), and transaction environment (e.g., construction market situation). Thus, correspondingly, the factors of PDCS selection can be mainly categorized into three groups, namely, transaction object-related factors, transaction subject-related factors, and transaction environment-related factors. The study involved a questionnaire survey in 2008 and finally determined 14 factors from the Chinese perspective, as shown in Table 3.

\section{PDCS Design: Process Model}

5.1. General Process Model. This paper regards DB and DBB as the two fundamental PDMs, while other PDMs can be taken as their variants. The PDCS design should be based on these two fundamental PDMs. In this paper, it is proposed that the design process of PDCS can be similar to that of an engineering structure, which usually includes the conceptual design, preliminary design, and detailed design. Accordingly, the PDCS design is divided into two stages, namely, preliminary design and detailed design. During the preliminary design, the $\mathrm{DB}$ or $\mathrm{DBB}$ will be selected as the framework or template for the next stage, detailed design, in which DB or DBB will be optimized for a specific project, and the PDM will be combined together with contract strategy and formed into different options that can be selected. For PDM only, one may select an existing method from the DB category or DBB category, and some changes can also be made to these existing methods to create a new derivative or variant of $\mathrm{DB}$ or $\mathrm{DBB}$.

The value-added analysis (VAA) will be conducted to make a decision in the design process. In the first stage, the relative potential added value of $\mathrm{DB}$ over $\mathrm{DBB}$ will be predicted and estimated. If the added value is positive, which means that $\mathrm{DB}$ is better than $\mathrm{DBB}$, then $\mathrm{DB}$ will be selected. Otherwise, $\mathrm{DBB}$ will be selected. In the second stage, the value-added analysis will be done on the project objectives by comparing different detailed options.

A general design model is shown as Figure 5.

5.2. Preliminary Design. As shown in Figure 5, the main task of the preliminary design is to determine which category of the PDM will be selected, namely, DBB or DB (including their variants). $\mathrm{DB}$ and $\mathrm{DBB}$ are the two fundamental PDMs, and one of them will be selected based on which the innovative PDM may need to be designed for a specific project; we will use the tool of the value-added analysis to make the decision. First of all, the value-added features of DB compared with DBB will be identified in terms of project objectives. Secondly, the potential added value corresponding to different valueadded features will be measured. Based on the first two steps, a model can be developed for the selection of DB or DBB. Figure 6 shows the steps of the preliminary design.

5.2.1. Identification of Value-Added Features. Compared with $\mathrm{DBB}$, the greatest advantage of $\mathrm{DB}$ is the integration of design and construction, which provides conditions and platform for engineering optimization and enhances the motivation of contractors to conduct the optimization. Besides, DB has the advantages of singular responsibility, which can reduce the work of coordination and supervision for the owner. Under these advantages, DB can achieve the added value, either through cost saving or schedule saving in terms of project goals. However, DB does not have advantages in terms of market competence over DBB; namely, $\mathrm{DB}$ may bring the negative added value. For different projects, the added value mentioned above is always different. Figure 7 (adapted from [59]) shows the main valueadded features and their effects on the project goals or performance.

5.2.2. Measurement of Added Value. In Figure 7, we can see that, under the premise that the quality and functional 


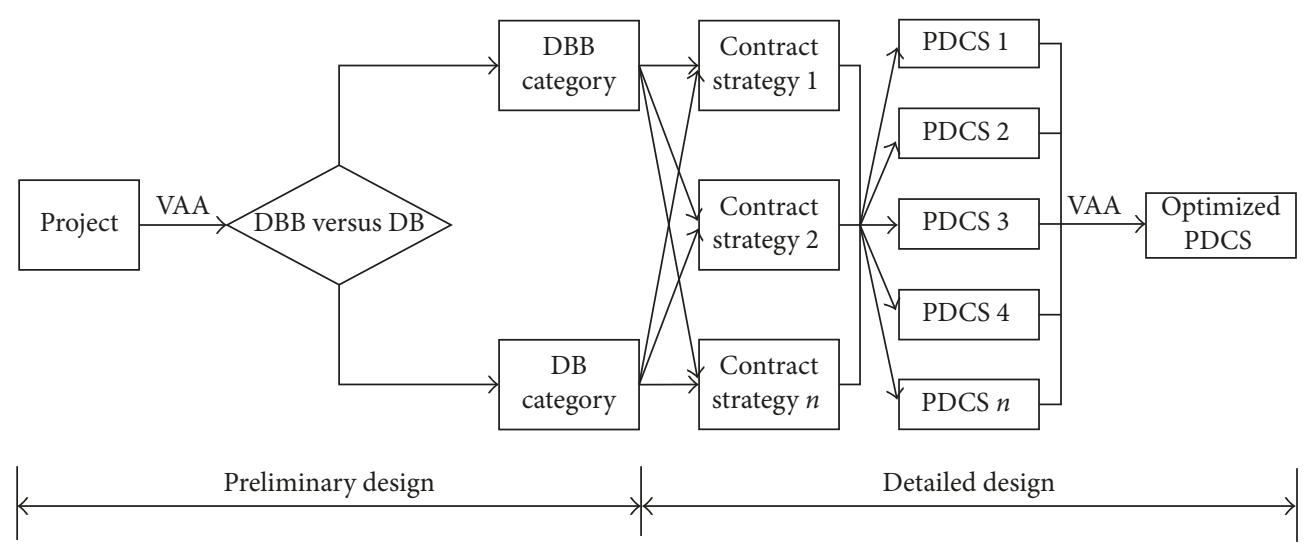

FIGURE 5: General process model for the PDCS design.

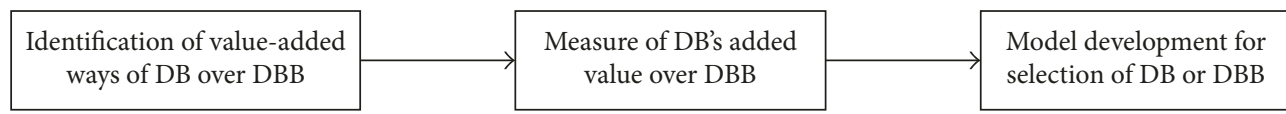

FIgURE 6: Steps of the preliminary design.

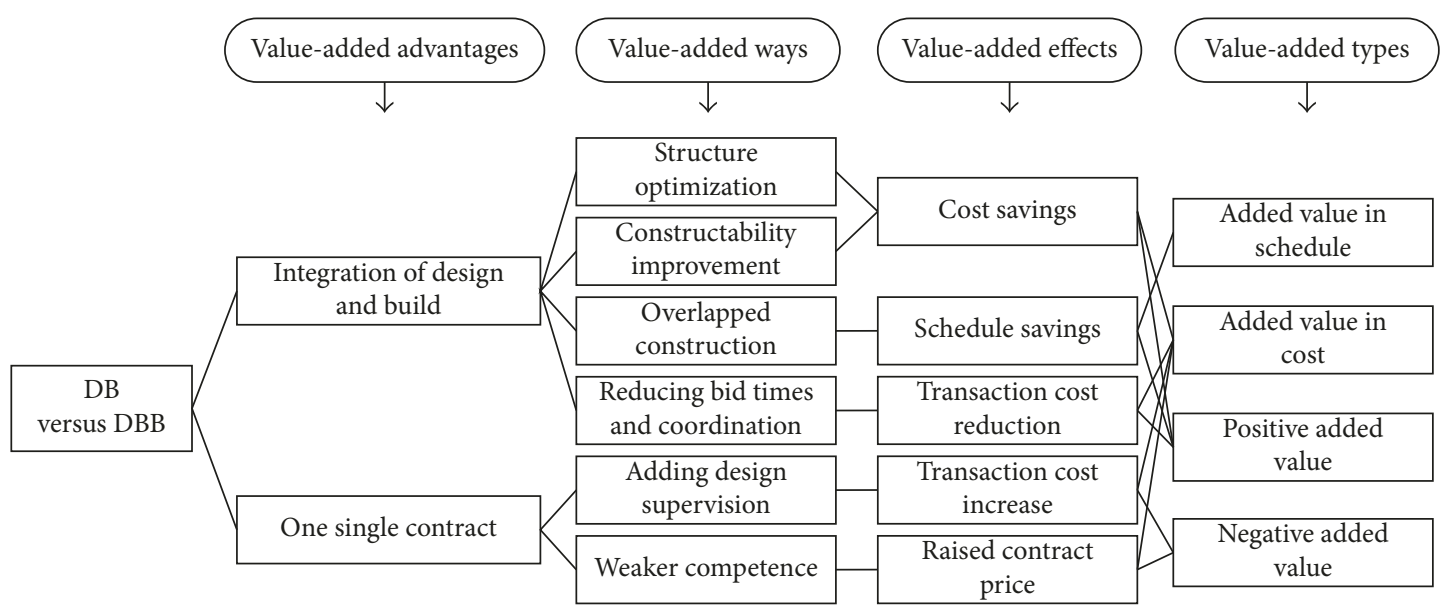

FIGURE 7: Main value-added features and their effects.

requirements are fixed, the added value can be classified into two kinds: added value in schedule and added value in cost. In order to measure them, we should first identify the factors affecting these two kinds of added value. As a matter of fact, there are several research projects on factors associated with project performance, project success, or project delivery system selection. These factors are similar, some of which are from the macroscopic view, while others from the microscopic view. According to the results we mentioned above, eight main factors are determined from the perspective of transaction as shown in Figure 8.

These factors may only affect one aspect of the added value or affect several or even all the aspects of the added value. According to Figures 5 and 8, an expert interview was conducted in a previous study to determine which factor will affect which aspects of the value added [59]. By doing this, an analysis matrix was developed as shown in Table 4 .

Through the analysis matrix, further study should be conducted to determine the relationships between the added value $\left(\Delta C_{1}, \Delta C_{2}, \Delta C_{3}\right.$, and $\left.\Delta T\right)$ and their factors. For example, as shown in Table $4, \Delta C_{1}$ is determined by quantity uncertainty $\left(x_{1}\right)$, project size $\left(x_{2}\right)$, contractor's capability $\left(x_{3}\right)$, and risk allocation $\left(x_{6}\right)$, so it can be expressed as

$$
\Delta C_{1}=f\left(x_{1}, x_{2}, x_{3}, x_{6}\right) \text {. }
$$

However, among $x_{1}, x_{2}, x_{3}$, and $x_{6}$, they are not independent, $x_{6}$ is dependent on other three factors; therefore, the estimate of $\Delta C_{1}$ needs to be simplified combining construction practice. Other added value also needs further study.

5.2.3. Model Development for $D B / D B B$ Selection. As mentioned by previous researchers, the basic project objectives include cost, schedule, and quality. So, for a specific project, if the relative added value (DB versus $\mathrm{DBB}$ ) in terms of all the project objectives are positive (lower cost and shorter time), namely, $\Delta C=\Delta C_{1}+\Delta C_{2}-\Delta C_{3}>0$ and $\Delta T>0$, then 


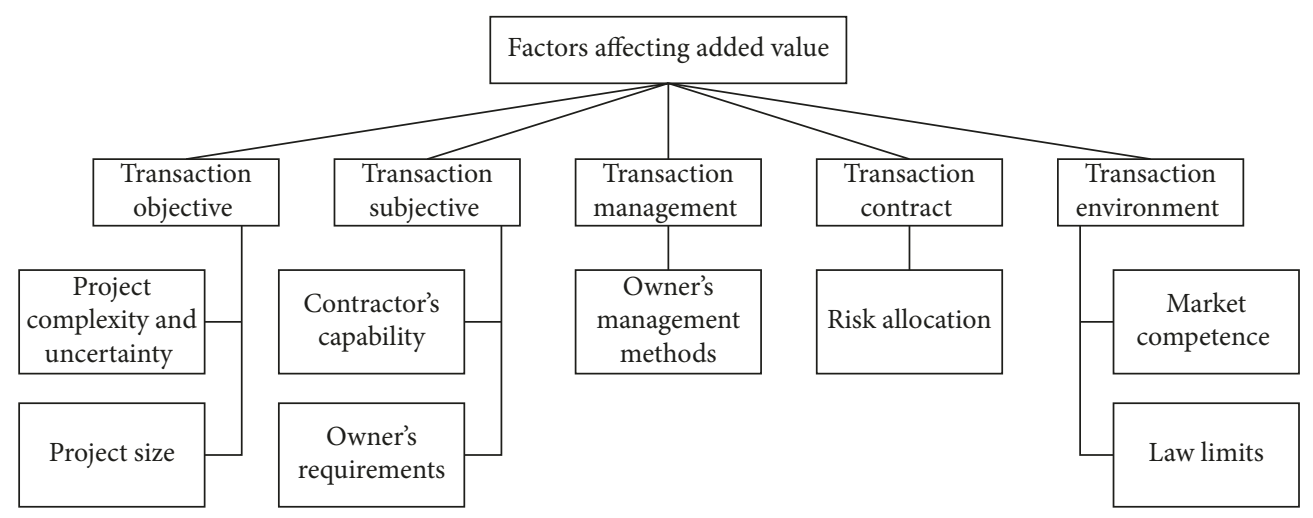

Figure 8: Main factors of the added value.

TABle 4: Value-added way analysis matrix.

\begin{tabular}{|c|c|c|c|c|c|}
\hline \multirow{3}{*}{ Transaction elements } & \multirow{3}{*}{ Factors } & \multicolumn{4}{|c|}{ Value-added features } \\
\hline & & \multicolumn{3}{|c|}{ Positive added value } & \multirow{2}{*}{$\begin{array}{c}\text { Negative } \\
\text { added value } \\
\text { Contract } \\
\text { price, } \Delta C_{3}\end{array}$} \\
\hline & & $\begin{array}{l}\text { Cost savings through } \\
\text { optimization, } \Delta C_{1}\end{array}$ & $\begin{array}{c}\text { Schedule } \\
\text { savings, } \Delta T\end{array}$ & $\begin{array}{l}\text { Transaction cost } \\
\text { reduction, } \Delta C_{2}\end{array}$ & \\
\hline \multirow{2}{*}{ Transaction object } & Quantity uncertainty $x_{1}$ & $\sqrt{ }$ & $\sqrt{ }$ & $\sqrt{ }$ & $\times$ \\
\hline & Project size $x_{2}$ & $\sqrt{ }$ & $\sqrt{ }$ & $\sqrt{ }$ & $\sqrt{ }$ \\
\hline \multirow{2}{*}{ Transaction subject } & Contractor's capability $x_{3}$ & $\sqrt{ }$ & $\sqrt{ }$ & $x$ & $x$ \\
\hline & Owner's requirements $x_{4}$ & $x$ & $\sqrt{ }$ & $x$ & $x$ \\
\hline Transaction management & Owner's supervision method $x_{5}$ & $x$ & $x$ & $\sqrt{ }$ & $x$ \\
\hline Transaction contract & Risk allocation $x_{6}$ & $\sqrt{ }$ & $\sqrt{ }$ & $x$ & $x$ \\
\hline Transaction environment & Market competence $x_{7}$ & $x$ & $x$ & $x$ & $\sqrt{ }$ \\
\hline
\end{tabular}

Note. " $\sqrt{ }$ " means that the corresponding value-added way has close relationship with the factor; " $x$ " means that the value-added way has no close relationship with the factor.

DB should be selected. However, not all the projects will have the same situation. Therefore, it is a multiobjective decision problem to determine which is to be selected between DB and DBB in most cases.

5.3. Detailed Design. The detailed design is based on the result of the preliminary design. When DB is selected in the preliminary design, the detailed design will be different from that when $\mathrm{DBB}$ is selected in the preliminary design because of the different characteristics of these two PDMs. However, the overall steps are similar. In the detailed design stage, the available PDMs belonging to $\mathrm{DB} / \mathrm{DBB}$, as well as available contract strategies, should be determined first of all; then combine the PDMs and contract strategies to get different PDCS options; and delete those options that are apparently not suitable for the specific project to get the feasible set of PDCS options. Finally, a decision should be made to choose the best one that can add most value to the project objectives. Figure 9 shows the steps for the detailed design of PDCS.

\section{Discussion}

The detailed design of PDCS depends on the result of the preliminary design. No matter which category is selected between DB and DBB in the preliminary design stage, there exist several options in the detailed design to be selected or new PDCS will be proposed. Under DBB, the project construction can be procured through general contracting (GC) or provided by multiple prime, which have different combinations. For different projects, different DBB options may produce different performance. Therefore, a reasonable decision should be made to select the best option. Similarly, there also exist different specific delivery methods under DB. For example, the design-builder can sign the contract with the owner either as soon as feasibility study is completed, or after the project preliminary design. However, it is a different decision process since $\mathrm{DB}$ is quite different from $\mathrm{DBB}$. Therefore, the detailed design of PDCS needs to be studied, respectively, for DB-based and DBB-based PDMs.

6.1. Detailed Design for DBB-Based PDMs. Under DBB, the construction is separated from the design, and thus, the main problem is to determine how the construction service will be procured. Under this situation, the objectives of quality and schedule have been decided. So when selecting/designing the best option for $\mathrm{DBB}$, we need to mainly consider the cost goal. The detailed design process of PDCS under DBB can be divided into three steps:

(i) Firstly, feasible option set under DBB should be established. According to the main characteristics of DBB and its variants, as well as the factors for the 


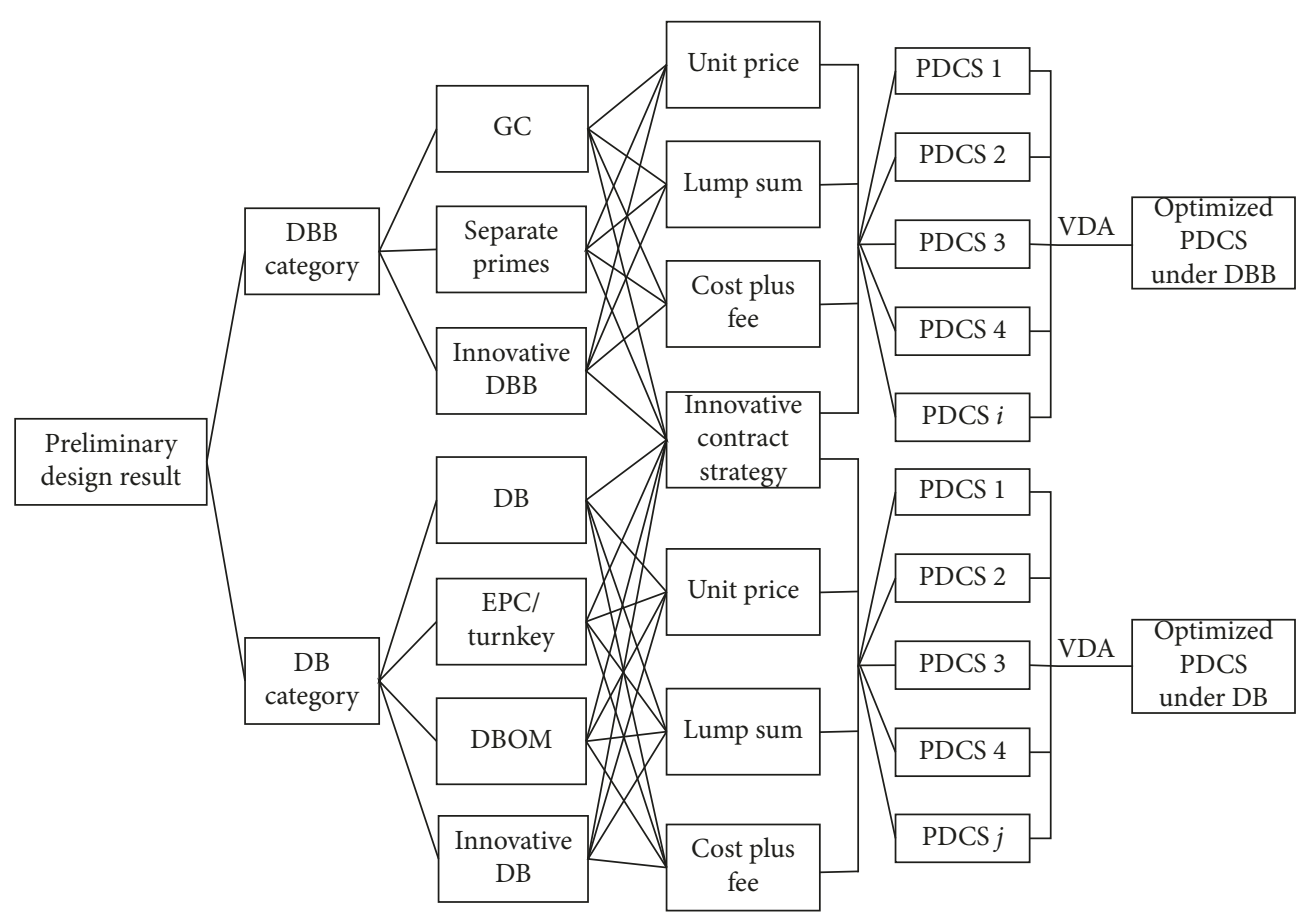

Figure 9: Steps for the detailed design of PDCS.

DBB design, we can list the feasible set of $\mathrm{DBB}$ and corresponding contract strategies that suited for the specific project. Then different combinations of PDM under DBB with contract strategy will be achieved. Remove the combinations that apparently do not match well for the given project. Thus, the feasible set of PDCS options form.

(ii) Secondly, the value-added analysis will be conducted to compare different PDCS options. As mentioned above, we only need to consider the cost goal under DBB. Thus, the main task is to seek a method to estimate the total cost under different PDCS options. The total cost includes production cost and transaction cost. So the estimation method should be based on project cost analysis theory and method, as well as transaction cost economics, with considerations of market situation and supervision difficulty.

(iii) Finally, the PDCS selection model will be developed based on the value-added analysis of cost objective. Under DBB, the schedule and quality are almost determined, and thus, the relative added value of different PDCS options is the cost savings, namely, added value in cost reduction. The best PDCS option can be selected by finding out the one with the greatest added value in cost conduction.

6.2. Detailed Design for DB-Based PDMs. Under DB, the detailed design process is similar to that of $\mathrm{DBB}$. But the optimization objective is different. Because design and construction are integrated under $\mathrm{DB}$, the optimization objective should include both cost and schedule. As to quality, no matter which kind of PDCS is adopted, quality objective is always fixed. Therefore, we need to pursue a method to estimate the added value of different PDCS options under DB, by considering both cost goal and schedule goal. Correspondingly, the selection model under $\mathrm{DB}$ will be a multiobjective decision.

6.3. Benefits of PDCS Design Approach. There are several benefits of the PDCS design approach:

(i) Designing PDCS makes it possible to customize the PDM and PCS with the specific features of specific projects. It also encourages innovation, not limited to existing PDMs.

(ii) Combining the PDM with PCS helps the owner that can optimize the decisions on a whole.

(iii) Designing the PDCS based on the value-added analysis of project objectives is a clearer and more direct path to make PDCS decision rather than existing methods.

6.4. Limitations of PDCS Design Approach. There are also some limitations of the PDCS design approach. On the one hand, it needs a lot of project data to estimate the added value. It is difficult to get these data, especially in developing countries like China. On the other hand, owners are familiar with old methods, and it needs time for them to realize the importance of the PDCS design.

\section{Conclusions}

At present, there are several PDMs available for the construction industry. However, there is no delivery system that is applicable to all kinds of projects. Most groups agree that 
there is no perfect project delivery method. Every project is unique and has its own unique set of challenges. Therefore, industry consensus is that every project should be considered on a case-by-case basis to determine the most appropriate project delivery method [17]. From this perspective, project delivery systems are products of the design and not simple selection. The PDM should be designed for the specific requirement of each specific and unique project. Besides, it is important to match the right contract strategy with the right project delivery option when selecting and implementing any project delivery option since the PDM cannot function independently without the support of reasonable contract strategies.

This paper focuses on the integrated design of the project delivery method and contract strategy, namely, PDCS design. The design process is divided into two steps, preliminary design and detailed design, similar to engineering structure design. In the preliminary design stage, one will be selected between the two fundamental PDMs, DBB and DB, as a basis for the detailed design. Then in the detailed design, the most proper variant will be selected or a new variant will be designed based on DB or DBB according to the result of the first step, and the contract strategy will be determined to match with the PDM. When selecting DB or DBB in the first stage and determine the variant of them in the detailed design, the value-added analysis of project objectives is conducted to make the decisions. Through the framework proposed in this paper, PDCS can be designed for a specific project to customize the PDM and PCS, making the project delivery method and contract strategy more consistent with project conditions and objectives and also promoting joint innovation of PDCS as a whole. In addition, the design of PDCS based on the value-added analysis may improve the directness and scientificalness of decision-making compared with existing methods.

However, this paper only puts forward a conceptual framework for the design of PDCS without case studies due to limited conditions. Firstly, the valuation of value-added benefits requires a lot of data from practice, which is difficult to be obtained under the current environment and information level of Chinese construction industry. Secondly, the owners are familiar with the traditional DBB model, and their innovation power is insufficient under the current system and related policies. Thirdly, the conceptual framework involves comprehensively several aspects of project transaction and calls for higher requirements for the owner's abilities. In view of the limitations of this paper, future research should focus on some empirical studies based on the proposed framework. The future works will conduct some validations and case studies, and lessons learned from which will be valuable for improving the framework. Also, the results of this study can be extended to the innovation of business models in both research and practices.

\section{Conflicts of Interest}

The authors declare that they have no conflicts of interest.

\section{Acknowledgments}

The authors would like to thank Professor Zhuofu Wang and Professor Chimay Anumba for their valuable advice for this article and wish to acknowledge the supports from the National Natural Science Foundation of China (Project no. 71402045) and the Fundamental Research Funds for the Central Universities (Project no. 2017B18114) that funded this research. The authors also thank the China Scholarship Council for supporting this study in the United States (Grant no. 201206710036).

\section{References}

[1] National Bureau of Statistics of P. R. China, The Economic Operation in 2017 was Better than Expected, January 2018, http://www.stats.gov.cn/tjsj/zxfb/201801/t20180118-1574917. html.

[2] R. M. Skitmore and D. E. Marden, "Which procurement system? Towards a universal procurement selection technique," Construction Management and Economics, vol. 6, no. 1, pp. 71-89, 1998.

[3] P. E. D. Love, R. M. Skitmore, and G. Earl, "Selecting a suitable procurement method for a building project," Construction Management and Economics, vol. 16, no. 2, pp. 221-233, 1998.

[4] P. E. D. Love, "Influence of project type and procurement method on rework costs in building construction projects," Journal of Construction Engineering and Management, vol. 128, no. 1, pp. 18-29, 2002.

[5] P. D. Rwelamila and R. Edries, "Project procurement competence and knowledge base of civil engineering consultants: an empirical study," Journal of Management in Engineering, vol. 23, no. 4, pp. 182-192, 2007.

[6] Z. F. Wang, G. S. Yang, and W. M. Hong, Construction Project Transaction Theories and Modes, China Waterpower Press, Beijing, China, 2010.

[7] J. Sullivan, M. E. Asmar, J. Chalhoub, and H. Obeid, "Two decades of performance comparisons for design-build, construction manager at risk, and design-bid-build: quantitative analysis of the state of knowledge on project cost, schedule, and quality," Journal of Construction Engineering and Management, vol. 143, no. 6, p. 04017009, 2017.

[8] G. Culp, "Alternative project delivery methods for water and wastewater projects: do they save time and money?," Leadership and Management in Engineering, vol. 11, no. 3, pp. 231-240, 2011.

[9] Y. Xu, Y. Wang, and B. Yao, "Study on the construction project IPD collaborative management based on building information model," China Civil Engineering Journal, vol. 44, no. 12, pp. 138-143, 2011.

[10] R. Pietroforte and J. B. Miller, "Procurement methods for US infrastructure historical perspectives and recent trends," Building Research and Information, vol. 30, no. 6, pp. 425-434, 2002.

[11] Guangdong Hydropower Planning and Design Institute (GHPDI), Critical Issues of DB Application in Water Projects Invested by Guangdong Government. A Report to the Water Resource Department of Guangdong Province, Guangdong Hydropower Planning and Design Institute (GHPDI), Guangzhou, China, 2011.

[12] Y. Q. Chen, J. Y. Liu, B. G. Li, and B. S. Lin, "Project delivery system selection of construction projects in China," Expert Systems with Applications, vol. 38, no. 5, pp. 5456-5462, 2011. 
[13] A. Mostafavi and M. Karamouz, "Selecting appropriate project delivery system: fuzzy approach with risk analysis," Journal of Construction Engineering and Management, vol. 136, no. 8, pp. 923-930, 2010.

[14] Z. F. Wang and Y. H. Jian, Construction Project Management: Modes and Innovations, China Waterpower Press, Beijing, China, 2006.

[15] P. B. Pishdad and Y. J. Beliveau, Analysis of Existing Project Delivery and Contracting Strategy (PDCS) Selection Tools with a Look Towards, Working Paper, 2013.

[16] S. Anderson and A. Oyetunji, "Selection procedure for project delivery and contract strategy," Journal of Construction Research, vol. 254, no. 3, pp. 1-9, 2003.

[17] J. Y. Ding, Z. F. Wang, C. Anumba, and D. G. Wang, "A review of research on delivery methods and project performance of construction projects," China Civil Engineering Journal, vol. 47, no. 4, pp. 131-144, 2014.

[18] Associated General Contractors of America, Project Delivery Systems for ConstructionAssociated General Contractors of America, Arlington, VA, USA, 3rd Edition, 2011.

[19] K. Ghavamifar, A Decision Support System for Project Delivery Method Selection in the Transit Industry, Ph.D. thesis, Northeastern University, Boston, MA, USA, 2009.

[20] M. Kenig, Understanding Project Delivery Method, 2007, http://www.agc.org/galleries/projectd/Kenig-20070321-PDS. pdf.

[21] Construction Industry Institute (CII), Project Delivery Systems: CM at Risk, Design-Build, Design-Bid-Build, Research Summary RS133-1, Austin, TX, USA, 1997.

[22] A. Touran, D. D. Gransberg, K. R. Molenaar, and K. Ghavamifar, "Selection of project delivery method in transit: drivers and objectives," Journal of Management in Engineering, vol. 27, no. 1, pp. 21-27, 2011.

[23] B. Liu, T. Huo, J. Meng, J. Gong, Q. Shen, and T. Sun, "Identification of key contractor characteristic factors that affect project success under different project delivery system: empirical analysis based on a group of data from China," Journal of Management in Engineering, vol. 32, no. 1, p. 05015003, 2016.

[24] P. Pakkala, Innovative Project Delivery Methods for Infrastructure-An International Perspective, Finnish Road Enterprise, Headquarters, Helsinki, Finland, 2002.

[25] C. B. Farnsworth, R. O. Warr, J. E. Weidman, and D. M. Hutchings, "Effects of CM/GC project delivery on managing process risk in transportation construction," Journal of Construction Engineering and Management, vol. 142, no. 3, p. 04015091, 2016.

[26] J. W. E. Masterman, An Introduction to Building Procurement Systems, E \& FN Spon, London, UK, 1992.

[27] A. D. Songer and K. R. Molenaar, "Selective design-build: public and private sector owner's attitudes," Journal of Management in Engineering, vol. 12, no. 6, pp. 47-53, 1996.

[28] C. J. Anumba and N. F. O. Evbuomwan, "Concurrent engineering in design-build projects," Construction Management and Economics, vol. 15, no. 3, pp. 271-281, 1997.

[29] K. Tenah, "The design-build project delivery system: an overview," Cost Engineering, vol. 42, no. 3, pp. 31-37, 2000.

[30] F. Sami and J. George, "Design-build delivery system on trial," AACE International Transactions -48th AACE International Annual Meeting, Washington, US, 2004.

[31] M. Konchar and V. Sanvido, "Comparison of U.S. project delivery system," Journal of Construction Engineering and Management, vol. 124, no. 6, pp. 435-444, 1998.
[32] V. Sanvido and M. Konchar, Selecting Project Delivery Systems: Comparing Design-Build, Design-Bid-Build, and Construction Management at Risk, The Project Delivery Institute, State College, PA, USA, 1999.

[33] M. S. Qiang, H. Wen, and S. G. Yuan, "Design-building and design-bidding-cost analysis of construction project implementation cost control meta-analysis," Journal of Tongji University, vol. 44, no. 3, pp. 482-490, 2016.

[34] E. M. Rojas and I. Kell, "Comparative analysis of project delivery systems cost performance in Pacific Northwest public schools," Journal of Construction Engineering and Management, vol. 134, no. 6, pp. 387-397, 2008.

[35] D. R. Hale, P. P. Shrestha, G. E. Gibson, and G. C. Migliaccio, "Empirical comparison of design/build and design/bid/build project delivery methods," Journal of Construction Engineering and Management, vol. 135, no. 7, pp. 579-588, 2009.

[36] J. W. Rosner, A. E. Thal, and C. J. West, "Analysis of the design-build delivery method in air force construction projects," Journal of Construction Engineering and Management, vol. 135, no. 8, pp. 710-717, 2009.

[37] S. Yun and W. Jung, "Benchmarking sustainability practices use throughout industrial construction project delivery," Sustainability, vol. 9, no. 6, p. 1007, 2017.

[38] M. S. Qiang, X. Wen, and H. C. Jiang, "Construction management model matching relationship and its impact on project performance," Journal of Tongji University: Natural Science Edition, vol. 43, no. 1, pp. 160-166, 2015.

[39] J. Ernzen and C. Schexnayder, "One company's experience with design/build: labor cost risk and profit potential," Journal of Construction Engineering and Management, vol. 126, no. 1, pp. 10-14, 2000.

[40] B. Franz, R. Leicht, K. Molenaar, and J. Messner, "Impact of team integration and group cohesion on project delivery performance," Journal of Construction Engineering and Management, vol. 143, no. 1, p. 04016088, 2016.

[41] P. P. S. Hrestha, Performance Benchmarking of Large Highway Projects, Ph.D. dissertation, University of Texas at Austin, Austin, TX, USA, 2007.

[42] T. Adams, Design-Build-Operate Gains Popularity in U.S. Market, Water World, 2003, http://www.waterworld.com/ articles/print/volume-19/issue-12/editorial-focus/design-buildoperate-gains-popularity-in-us-market.html.

[43] S. M. Bogus, J. Shane, and K. R. Molenaar, Independent Comparative Evaluation of Design-Build v. Conventional Design-Bid-Build Project Delivery for Municipal Water and Wastewater Facilities, Report Prepared for the Water DesignBuild Council, Water Design-Build Council, Washington, DC, USA, 2009.

[44] J. S. Shane, S. M. Bogus, and K. R. Molenaar, "Municipal water/wastewater project delivery performance comparison," Journal of Management in Engineering, vol. 29, no. 3, pp. 251-258, 2013.

[45] H. S. Park, D. Lee, S. Kim, and J. K. Kim, "Comparing project performance of design-build and design-bid-build methods for large-sized public apartment housing projects in Korea," Journal of Asian Architecture and Building Engineering, vol. 14, no. 2, pp. 323-330, 2015.

[46] J. Park and Y. H. Kwak, "Design-bid-build (DBB) vs. designbuild $(\mathrm{db})$ in the U.S. public transportation projects: the choice and consequences," International Journal of Project Management, vol. 35, no. 3, pp. 280-295, 2016.

[47] C. T. W. Chan, "Fuzzy procurement selection model for construction projects," Construction Management and Economics, vol. 25, no. 6, pp. 611-618, 2007. 
[48] B. Xia, A. P. C. Chan, and J. F. Y. Yeung, "Developing a fuzzy multi-criteria decision-making model for selecting design-build operational variations," Journal of Construction Engineering and Management, vol. 137, no. 12, pp. 1176-1184, 2011.

[49] A. Heidemann and F. Gehbauer, "The way towards cooperative project delivery," Journal of Financial Management of Property and Construction, vol. 16, no. 1, pp. 19-30, 2011.

[50] D. Bowers, R. Bhargava, and S. Anderson, Characteristics of Integrated Project Delivery and Contract Strategies, A Report to CII (No. Research Report 165-11), The University of Texas, Austin, TX, USA, 2003.

[51] S. Korkmaz, M. Horman, and D. Riley, "Key attributes of a longitudinal study of green project delivery," in Proceedings of the Construction Research Congress 2009: Building a Sustainable Future, Seattle, WA, USA, April 2009.

[52] A. P. C. Chan, D. Scott, and E. W. M. Lam, "Framework of success criteria for design/build projects," Journal of Management in Engineering, vol. 18, no. 3, pp. 120-128, 2002.

[53] T. R. Warne and J. L. Beard, Project Delivery Systems owner's Manual, American Council of Engineering Companies, Washington, DC, USA, 2005.

[54] T. Alhazmi and R. McCaffer, "Project procurement system selection model," Journal of Construction Engineering and Management, vol. 126, no. 3, pp. 176-184, 2000.

[55] M. I. A. Khalil, "Selecting the appropriate project delivery method using AHP," International Journal of Project Management, vol. 20, no. 6, pp. 469-474, 2002.

[56] Georgia State Financing and Investment Commission (GSFIC), Selecting the Appropriate Project Delivery Option: Recommended Guidelines, Georgia State Financing and Investment Commission, Atlanta, GA, USA, 2003.

[57] I. M. Mahdi and K. Alreshaid, "Decision support system for selecting the proper project delivery method using analytical hierarchy process (AHP)," International Journal of Project Management, vol. 23, no. 7, pp. 564-572, 2005.

[58] F. Mafakheri, L. Dai, D. Slezak, and F. Nasiri, "Project delivery system selection under uncertainty: multicriteria multilevel decision aid model," Journal of Management in Engineering, vol. 23, no. 4, pp. 200-206, 2007.

[59] Z. F. Wang, J. Y. Ding, D. G. Wang, and Y. Zhu, "Decisionmaking analysis framework for application of lump-sum contracting in hydropower projects from value-added perspective," Journal of Hydroelectric Engineering, vol. 33, no. 6, pp. 317-323, 2013. 


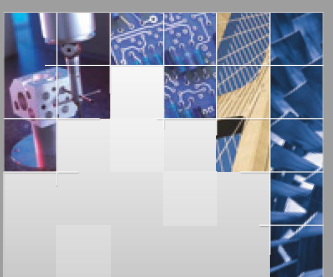

\section{Enfincering}
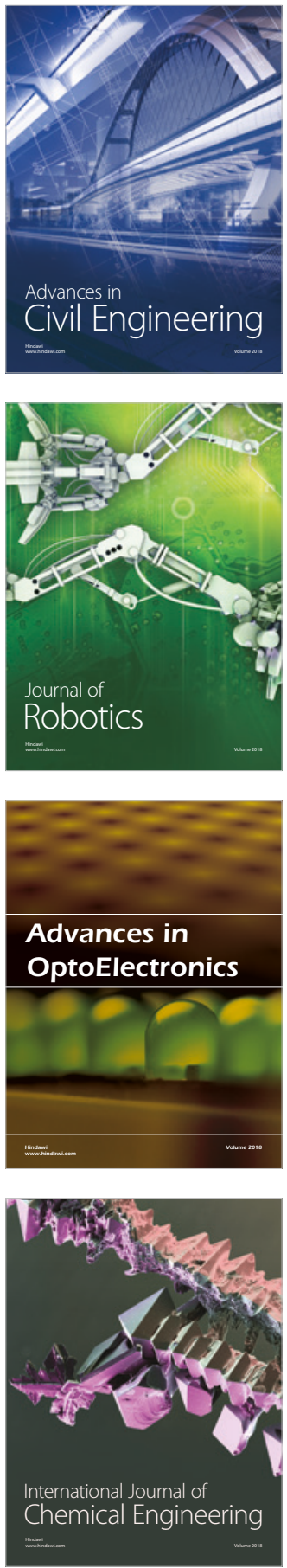

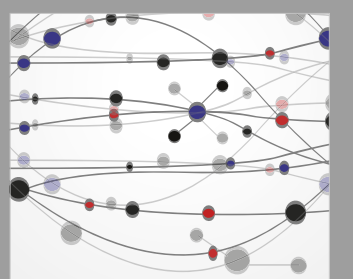

\section{Rotating \\ Machinery}

The Scientific World Journal

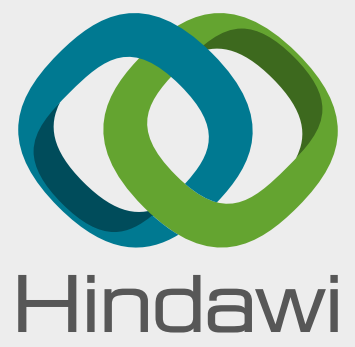

Submit your manuscripts at

www.hindawi.com
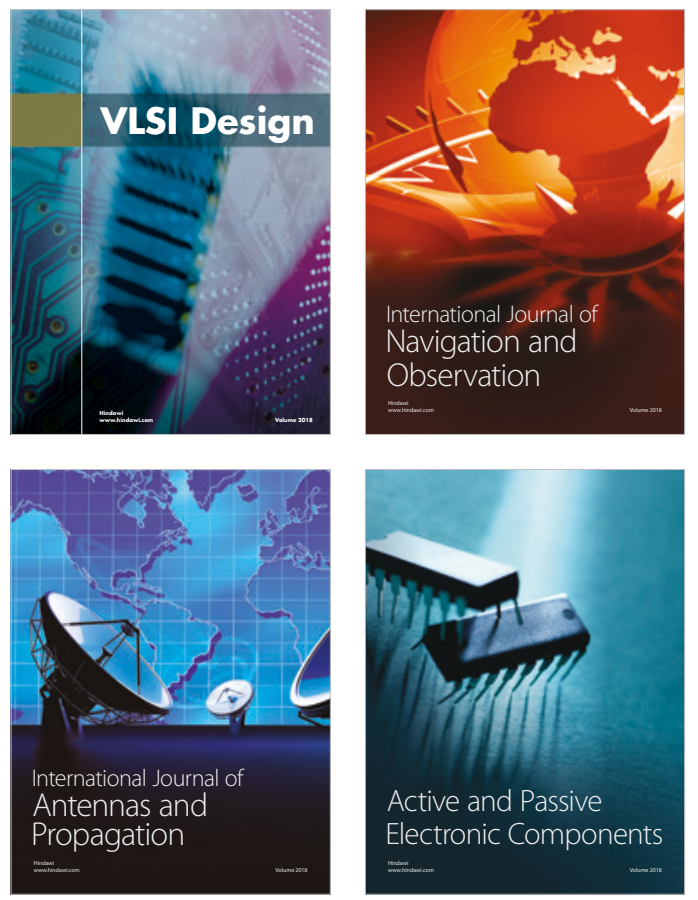
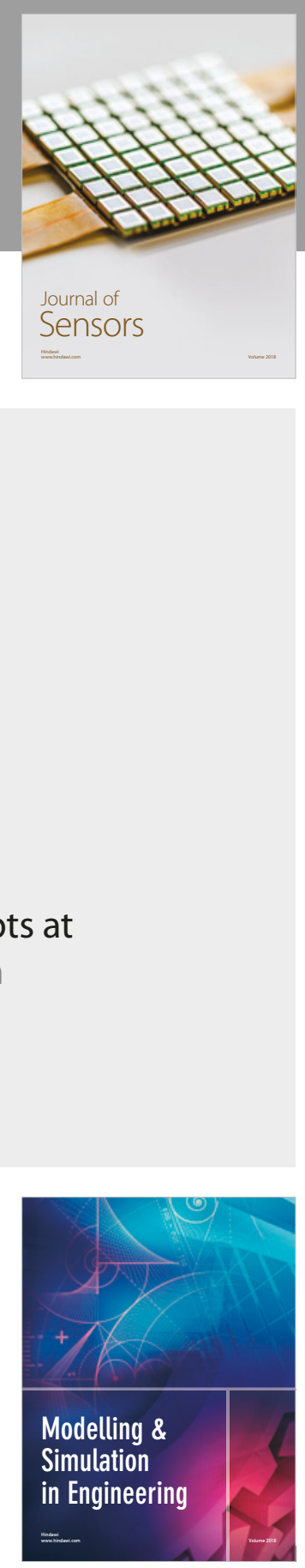

\section{Advances \\ Multimedia}
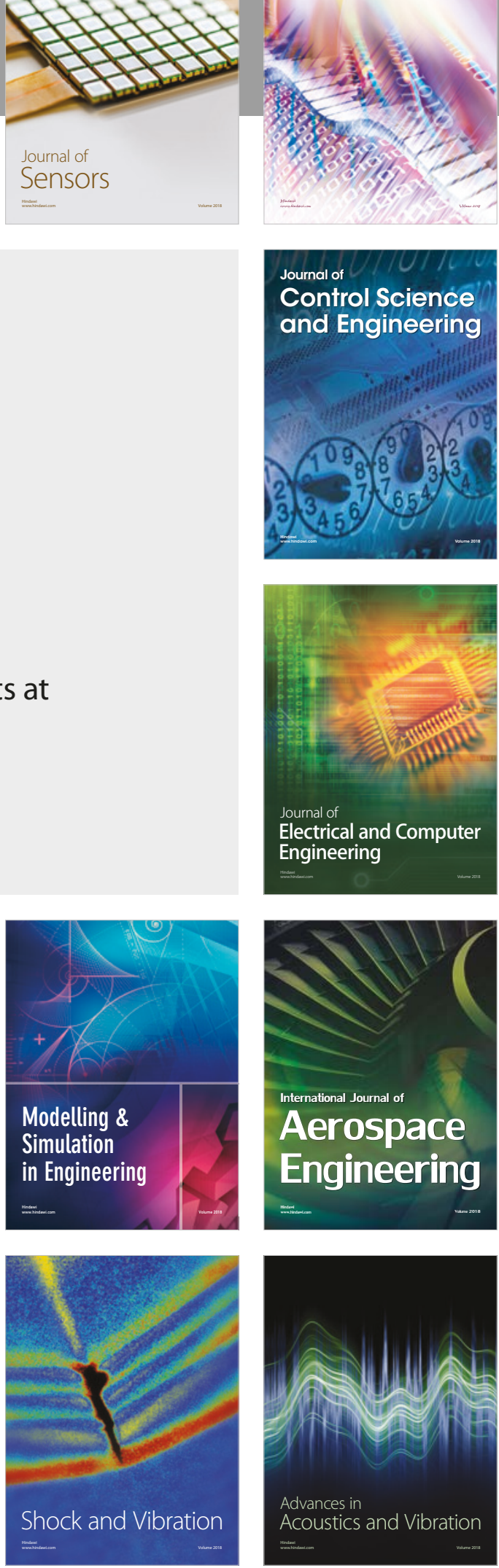